\title{
Lessons from a pandemic: do not force your patients into the bed of Procrustes!
}

\author{
Theodor Alexandru Voiosu ${ }^{1}$ and Andrei Mihai Voiosu ${ }^{1}$ \\ ${ }^{1}$ Spitalul Clinic Colentina
}

October 1, 2020

\begin{abstract}
The frantic search for a cure or prophylactic treatment of COVID-19 has unfortunately led to a dropping of the guard of many medical specialists resulting in widespread adoption of unproven treatment modalities. The recent article regarding the inconsistent physician attitudes towards hydroxychloroquine paints a depressing picture of the actual practices during the so-called era of evidence-based medicine. On this backdrop, we comment on how Romania (where this survey took place) has imposed some of the most severe lockdown measures in Europe, including the forced hospitalization of all confirmed with SARS-CoV-2 infection. Additionally, a therapeutic guideline was written into law, endorsing concomitant use of several drugs with unproven antiviral efficiency. This unprecedented situation has resulted in the sometimes indiscriminate prescription of off-label drugs, with a non-negligible risk of adverse reactions, especially in fragile patients with coexisting conditions. In light of the experience accrued in a COVID-19 dedicated unit, the authors discuss the importance of avoiding polypharmacy and administering all antiviral drugs within the confines of rigorously conducted clinical trials.
\end{abstract}

\section{Lessons from a pandemic: do not force your patients into the bed of Procrustes!}

\section{Theodor Voiosu ${ }^{1,2}$, Andrei Voiosu ${ }^{1}$}

1. Colentina Clinical Hospital, Gastroenterology Department, Bucharest

2. Carol Davila University of Medicine and Pharmacy, Bucharest

Corresponding author - Theodor Voiosu, Colentina Clinical Hospital, Gastroenterology Department, 19-21 Stefan cel Mare Bvd, Bucharest, Romania. email - theodor.voiosu@gmail.com

Keywords - COVID-19, SARS-Cov-2, polypharmacy, drug-related adverse events

We have read with great interest the article by Baicus et al.[1] regarding physician practice and attitudes towards hydroxychloroquine use during the COVID-19 pandemic and we would like to add to the context of their findings.

For the past months the medical community has been engaged in the search for efficient treatment and a staggering amount of conflicting primary and secondary data has appeared in a brief period of time [2]. Fast-track pathways for peer review were put in place in order to ensure vital data reaches the community promptly but, unfortunately, this has also meant that standards for acceptance were sometimes lowered and, occasionally, even leading journals published articles of low-quality that were ultimately retracted [3]. More importantly, many physicians rushed to embrace the use of one or several drugs with uncertain benefits but well-documented side effects, employing them outside the setting of rigorous clinical trials [4]. This approach is known to cause patients significant harm, as proven in the previous SARS-CoV 2003 pandemic with studies of ribavirin as a potential antiviral [5]. 
The very essence of evidence-based medicine lies in rigorous interpretation of quantifiable variables that ideally are recorded in an unbiased manner. Therefore, while case series and retrospective observational studies may provide correct information, it is generally accepted that stringently designed, preferably multicenter, double-blinded, prospective studies of different populations offer better quality data. Only a handful of these studies or preliminary reports $[6,7]$ looking at relevant endpoints are available (and liable to differ from their final printed form) and their results are generally much more conservative than initial reports [8]. In the end, in the patient-centered approach the medical professional has a duty and responsibility to evaluate the data and, together with the patient, decide the best option through shared decision-making.

While this is hopefully true in most settings, the exceptional healthcare crisis we are experiencing has led to the overloading of medical systems and the appearance of ethical dilemmas [9] which increase the risk for physician burnout and errors. Working in a COVID-19 dedicated unit, the authors have witnessed firsthand the price that patients can pay when time-tested scientific approaches to treatment are supplanted by use of unproven therapeutic agents.

At the beginning of the pandemic, Romanian authorities imposed some of the most severe lockdown measures in Europe, including the forced hospitalization of all COVID-19 patients with the provision that discharge was "legal" only after two consecutive negative PCR tests for SARS-CoV-2. The situation lasted for over 3 months [10]. Furthermore, the Health Ministry issued a series of treatment guidelines which were written into law [11] with the aim of enforcing a uniform approach to therapy. Although the stated aim of this twopronged approach was to assist hospital drug policy commissions and offer guidance on initially promising "off-label" drugs [12], we contend that this strategy with its' poorly phrased documentation encouraged doctors to abdicate from critical case-based decision-making and resulted in polypharmacy, with unclear benefits but with confirmed and sometimes severe drug-related adverse events.

More recently and at a time when regulatory bodies such as the Food and Drug Administration were revoking the Emergency Use Authorization of some drugs such as hydroxychloroquine [13], based on emerging data suggesting a lack of efficacy and a potential for severe drug-related adverse events, the Romanian Ministry of Health was issuing additional national protocols encouraging the almost indiscriminate use of a wide range of medications, including, but not limited to - hydroxychloroquine, remdesivir, ritonavir/lopinavir, favipiravir, tocilizumab, anakinra, corticosteroids and anticoagulants [12].

This "one-size fits all" approach to clinical practice has probably resulted in a significant number of drugrelated adverse events, although the precise impact is impossible to assess and, very likely, will never be comprehended fully. It is obvious that there is a high potential risk of drug-drug interaction in the setting of COVID-19 treatment especially in frail, polymedicated patients [14]. Despite these considerations, most severely ill patients admitted in the ICU of our unit have likely received and continue to receive concomitant off-label therapy with combinations of Tocilizumab, Hydroxychloroquine, Azithromycin and Lopinavir/Ritonavir, outside of well-structured clinical studies, in line with official recommendations which have not been updated for several months. We strongly believe that more critical review of the standard medical treatment in this patient group should counterbalance the state-endorsed polypharmacy and is the responsibility of each attending physician.

With the pandemic evolving at a rapid pace, physicians should consider that best supportive care and avoidance of additional harm incurred through off-label prescription of drugs with unproven efficacy could be the best way to help our patients. Until well-conducted clinical trials establish clear basis for antiviral prescription in COVID-19 we should all approach this extraordinary situation with humility and equipoise, in the best interest of our patients.

Acknowledgements: The authors would like to acknowledge the contribution of Georgiana Stoian and Ruxandra Prusan, currently involved in the Liver-COVID study, for contributing important insight for writing this paper. Also, the authors would like to acknowledge the hard work and dedication of all their fellow physicians and nursing staff involved in caring for COVID-19 patients at Colentina Clinical Hospital.

REFERENCES: 
1. Baicus C, Pinte L, Stoichitoiu LE, Badea C. Hydroxychloroquine for prophylaxis of COVID-19 physicians survey: Despite lack of evidence, many would take or give to dear ones, and despite the perceived necessity of an RCT, few would participate. J Eval Clin Pract. 2020 Sep 21. doi: 10.1111/jep.13484. Epub ahead of print. PMID: 32955801.

2. https://pubmed.ncbi.nlm.nih.gov/?term $=$ covid $+19+$ treatment\&sort $=$ pubdate $\&$ size $=50$, accessed $22^{\text {nd }}$ of September, 2020

3. https://www.thelancet.com/journals/lancet/article/PIIS0140-6736(20)311806/fulltext\#articleInformation [accessed 21 September 2020]

4.https://www.nejm.org/doi/full/10.1056/NEJMoa2007621 [accessed 21 September 2020]

5. Stockman LJ, Bellamy R, Garner P. SARS: systematic review of treatment effects. PLoS Med 2006;3(9):e343-e343.

6. McMahon JH, Udy A, Peleg AY. Remdesivir for the Treatment of Covid-19 - Preliminary Report [published online ahead of print, 2020 Jul 10]. N Engl J Med. 2020;383:10.1056/NEJMc2022236\#sa2. doi:10.1056/NEJMc2022236

7. RECOVERY Collaborative Group, Horby P, Lim WS, et al. Dexamethasone in Hospitalized Patients with Covid-19 - Preliminary Report [published online ahead of print, 2020 Jul 17]. N Engl J Med. 2020;10.1056/NEJMoa2021436. doi:10.1056/NEJMoa2021436

8. Annangi S. Chloroquine and hydroxychloroquine for COVID-19: A word of caution. Respirology. 2020;25(7):683-684. doi:10.1111/resp.13845

9. https://theconversation.com/coronavirus-allocating-icu-beds-and-ventilators-based-on-age-isdiscriminatory-136459 [accessed September 22nd 2020]

10. http://www.ms.ro/2020/06/23/modificarea-criteriilor-de-externare-pentru-pacientii-cu-afectiuneacovid-19/ - accessed July 22nd 2020

11. https://lege5.ro/Gratuit/gm3tcmbyguzq/ordinul-nr-860-2020-privind-modificarea-anexei-la-ordinulministrului-sanatatii-nr-487-2020-pentru-aprobarea-protocolului-de-tratament-al-infectiei-cu-virusul-sarscov-2 - accessed July 22nd 2020

12. http://www.cnscbt.ro/index.php/lex/1591-ordinul-nr-487-2020-pentru-aprobarea-protocolului-detratament-covid/file; accessed July 22nd 2020

13. https://www.fda.gov/media/138945/download

14. Lemaitre F, Solas C, Grégoire M, et al. Potential drug-drug interactions associated with drugs currently proposed for COVID-19 treatment in patients receiving other treatments [published online ahead of print, 2020 Jun 30]. Fundam Clin Pharmacol. 2020;10.1111/fcp.12586. doi:10.1111/fcp.12586 